\title{
Comparison of factors influencing patient choice of community pharmacy in Poland and in the UK, and identification of components of pharmaceutical care
}

\author{
This article was published in the following Dove Press journal: \\ Patient Preference and Adherence \\ 14 May 2014 \\ Number of times this article has been viewed
}

\author{
Piotr Merks' \\ Justyna Kaźmierczak ${ }^{2}$ \\ Aleksandra Elzbieta \\ Olszewska ${ }^{3}$ \\ Maria Kołtowska- \\ Häggström ${ }^{4}$ \\ 'Department of Pharmaceutical Care, \\ Medical University of Warsaw, Poland; \\ ${ }^{2}$ Department of Hygiene, Bioanalysis \\ and Environmental Studies, Medical \\ University of Silesia, Katowice, Poland; \\ ${ }^{3}$ Department of Pharmacy, Ashford \\ and St Peter's Hospitals National \\ Health Service Trust, Guildford Road, \\ Chertsey, Surrey, United Kingdom; \\ ${ }^{4}$ Department of Women's and \\ Children's Health, Uppsala University, \\ Uppsala, Sweden
}

Background: Several factors, which are components of pharmaceutical care, can influence a patient's choice of a community pharmacy store and contribute to frequent visits to the same pharmacy.

Objectives: To compare factors that influence a patient's choice of pharmacy in Poland and in the UK, to identify which of them are components of pharmaceutical care, and to relate them to patient loyalty to the same pharmacy.

Methods: A self-administered, anonymous questionnaire was distributed to clients visiting pharmacies in Poland and the UK January-August 2011. Comparisons were performed using chi-square tests and logistic regression. All statistical analyses were performed using SPSS 20.0. Results: The response rate was 55.6\% ( $n=417 / 750 ; 36$ pharmacies) and 54.0\% $(n=405 / 750$; 56 pharmacies) in Poland and in the UK, respectively. The most frequently reported factors, as defined by a percentage of responders, were in Poland: 1) location (84\%); 2) professional and high-quality of service (82\%); 3 ) good price of medicines $(78 \%)$; and 4 ) promotions on medicines $(66 \%)$. In the UK, the most commonly reported factors were: 1) professional and high quality of service (90\%); 2) location (89\%); 3) good advice received from the pharmacist $(86 \%)$; and 4$)$ option of discussing and consulting all health issues in a consultation room (80\%). Good advice and an option of discussing personal concerns with a pharmacist are components of pharmaceutical care. Thirty-eight percent of patients in Poland and $61 \%$ in the UK declared visiting the same pharmacy.

Conclusion: Components of pharmaceutical care are important factors influencing the patient's choice of pharmacy in the UK and, to a lesser degree, in Poland. Additionally, more patients in the UK than in Poland are committed to a single pharmacy. Therefore, implementing the full pharmaceutical care in Poland may contribute to an increase in patient loyalty and thus strengthen competitiveness of pharmacy businesses.

Keywords: pharmacy choice, patient's preferences, pharmaceutical care, patient-reported outcomes (PRO), health care system

\section{Introduction}

\section{Pharmaceutical care}

Pharmaceutical care ${ }^{1}$ was defined in the late 1980s of the 20th century in the US as a way to ensure safe and effective use of medicines. Pharmaceutical care facilitates the recognition, solving, and prevention of problems associated with the use of medicinal products, as well as the provision of information necessary for patient safety. ${ }^{2}$ The essential elements of pharmaceutical care have been named in the past to be:
Correspondence: Piotr Merks

Department of Pharmaceutical Care,

Medical University of Warsaw, ul Banacha

I, 02-097 Warsaw, Poland

Tel +48225720979

Fax +48 225720985

Email piotr.merks@wum.edu.pl 
involving patients in their own care by offering an option to discuss health and drug-related issues with the pharmacist; screening patient medication records stored in a pharmacy (usually on a computer system) to find patients who would benefit from a discussion with the pharmacist; helping patients achieve their individual treatment goals; and, lastly, developing and maintaining a positive relationship with the patient's physician for all three stakeholders patient, patient's physician, and pharmacist - to be equally involved in the patient's treatment. Pharmaceutical care also means that the pharmacist must take responsibility for the patient's pharmacological needs and is held liable for this obligation. An appropriately designed and well-managed pharmacological therapy is delivered to achieve positive patient outcomes. ${ }^{3}$ Overall, a considerable number of studies confirmed a positive impact of pharmaceutical care on treatment outcomes. ${ }^{4-10}$ Despite a substantial evidence of benefits related to pharmaceutical care, such care is not yet implemented in Poland. Also, Polish pharmacists are not legally obliged by the Polish Pharmacy Law, established in 1991, to be actively involved in the treatment process by providing pharmaceutical care. ${ }^{11}$

In 2000, efforts were undertaken in the UK to strengthen the role of the pharmacist and to give a new direction for the pharmacy profession to be more involved in the public health programs. ${ }^{12}$ As a consequence, all community pharmacies in the UK have implemented advanced pharmaceutical care in $2005 .^{13}$ The role of pharmacists has been expanded to include a range of new services that were placed in daily practice since the NHS Community Pharmacy contract for England and Wales was launched. ${ }^{14}$

\section{Patients' choice of pharmacy}

Patients report many factors that influence their choice of a pharmacy. These factors show that the patients' decisions are based on multiple and various grounds. Factors described by Wirth et $\mathrm{al}^{15}$ were: pharmacy location (indicated by $80 \%$ of patients); friendly staff (44\%); fast service (29\%); and appearance of a pharmacy (17\%). Similar outcomes were shown in Qatar, where the location of a pharmacy ( $90 \%$ of respondents), provision of a good range of products and services (79\%), convenient pharmacy opening hours (76\%), and pharmacist's professional knowledge $(66 \%)$ were considered primary choice factors. ${ }^{16}$ Additionally, full pharmaceutical care, as well as its separate components, may play an important role in patients' choice of a pharmacy.

According to the study of Wirth et $\mathrm{al}^{15}$ patients are more likely to visit a pharmacy that offers patient counselling. ${ }^{15}$
Studies conducted in the UK, the Netherlands, South Africa, and Japan also confirmed that availability of expertise, clear advice, and professional services constitute the essential criteria of pharmacy choice. ${ }^{17-21}$

Further studies confirmed the high influence of an opportunity to discuss health issues in a private consultation room on a patient's choice of pharmacy. ${ }^{22,23}$

Finally, it can be speculated that the price of medicines should also govern the choice of pharmacy, at least in the countries with high copayment and differences in price across pharmacies.

Poland and the UK are two countries with very different health insurance and drug reimbursement systems. In Poland, there are three categories of rate of payment for prescribed medicines: 1) a very low fixed charge, irrespective of the market price; 2) charge equal to $30 \%-50 \%$ of the market price; and 3) full market price. ${ }^{24}$ Overall, copayment in Poland is relatively high, which makes prescription medicines expensive for patients. Therefore, many people cannot afford their prescribed medication. ${ }^{25}$ In Britain, the health care system allows easier access to medicines as all prescribed medicines incur the same charge, irrespective of market prices. Certain groups of patients are exempt from this charge altogether (for example, all aged $0-16$ years old and $>60$ years old). Those who are not exempt from charges pay a fixed price for every item on a prescription - also irrespective of the market price. It is also possible to purchase a prepayment prescription certificate for a fixed price, which covers all medicines prescribed within a 3 - or 12 -month period. ${ }^{26}$

The extent to which price influences a choice of pharmacy and how it positions among other factors, (particularly, the components of pharmaceutical care), at the moment, is largely unknown. Similarly, the country-specific differences in factors of patient choice of pharmacy are explained to a very little extent. This particularly applies to countries with different healthcare systems and therefore different levels of pharmaceutical care, such as to Poland and the UK. Therefore, further research in this field facilitates understanding the factors that govern patient decision-making regarding the choice of pharmacy.

\section{Objectives}

The aim of the study was to compare factors that influence patient choice of pharmacy in Poland and in the UK, and most of all - to identify which of these factors are elements of pharmaceutical care. An additional objective was to examine the relationships between: patients' pharmacy selection criteria; patients' demographic characteristics, 
and their profile of use of pharmacy services, particularly their loyalty to the same pharmacy. Therefore, this study is the first step toward understanding how the introduction of individual elements of pharmaceutical care can increase patients' loyalty to a pharmacy.

\section{Methods}

This was a cross-sectional study with a self-administered, anonymous questionnaire distributed to clients during their visit to a community pharmacy in Poland and in the UK January-August 2011. All participants were informed about the study's anonymity, purpose, and design; participants were advised that by returning completed questionnaires they gave their consent to participation in the study. No particular inclusion and exclusion criteria were applied to the participants. Only patients who came to the pharmacy to fill the prescription were included in the study. Patients who returned incomplete questionnaires (maximum 10\% of questions left unanswered) were considered as nonresponders.

\section{Questionnaire}

The questionnaire, which consisted of 31 questions, was divided into two parts. The first part (26 questions) related to demographic information (sex, age, marital status, education, occupation, and place of residence) and self-reported assessment of the current profile of the use of pharmacy services (frequency of and reasons for their visit to the pharmacy, the number of filled prescriptions per month, and the tendency to visit the same pharmacy).

The second part of the questionnaire included questions regarding factors that influenced the patients' choice of pharmacy. The responders assessed, according to a 5-point ranked Likert scale the following factors: good advice received from the pharmacist; option of discussing health issues in the consultation room; design, appearance of the pharmacy, and appearance of the pharmacy staff; professionalism and quality of service; location of the pharmacy; good price of medicines; and promotions on medicines. Good advice and the option of discussing health issues in the consultation room are components of pharmaceutical care. ${ }^{1,22,23}$ The respondents chose one statement that best described the impact of each factor on their choice of pharmacy: 1) definitely has no influence; 2) rather has no influence; 3) unsure; 4) rather has influence; or 5) definitely has influence.

The questionnaire was available in Polish and in English and was either answered in the pharmacy and returned immediately as a hard copy or sent back via email.
The questionnaire development was based on the literature review and included assistance of a medical psychologist. Face and content validity, reliability, applicability, and practicality of the questionnaires were tested by two focus groups with ten participants each. A cognitive interview was part of the focus groups.

\section{Statistical methods}

Statistical analyses were performed using the SPSS statistical software, version 20 (IBM Corporation, Armonk, NY, USA). The number and proportion of respondents who reported factors as having influence were computed by combining rate $1-3$ (set to 0 ; ie, no/low influence) and rate 4 and 5 (set to 1 , influence) from the Likert scale. Fisher's exact test and $\chi^{2}$ test (for categorical variables) were conducted to test differences between groups. A $P$-value of $\leq 0.05$ indicated statistical significance. Odds ratios (ORs) and 95\% confidence intervals (CIs) were calculated using multivariate stepwise forward logistic regression analyses. Categorical predictors used in logistic multivariate regression analysis were: country; sex; age $<40$ years; university education; married; student; health care worker; white collar worker; rural resident (living in a community inhabited with up to 100,000 inhabitants); visiting a pharmacy one to two times a week; preference for one and the same pharmacy; and respondents with more than three prescriptions per month. The details of the coding system are presented in Table 1.

As measures of model fit the Hosmer-Lemeshow test $^{27}$ and Nagelkerke's $R^{2}$ were applied. It is a measure of model fit and the value of the test should at least be $>0.05$, the higher the better $R^{2}$ corresponds to $R^{2}$ in linear

Table I Codes used in the logistic regression

\begin{tabular}{lll}
\hline Codes & $\mathbf{0}$ & I \\
\hline Country & PL & UK \\
Sex & Male & Female \\
Age & $>39$ years & $<40$ years \\
University & Up to secondary & University \\
Married & No & Yes \\
Student & No & Yes \\
Health care worker & No & Yes \\
White collar worker & No & Yes \\
Rural area $\leq 100,000$ inhabitants & No & Yes \\
Frequency of visits to pharmacy & Less frequent & I-2 times \\
& & a week \\
Loyalty, visiting the same pharmacy & No & Yes and \\
\# of prescriptions/month & & rather yes \\
\hline
\end{tabular}

Abbreviations: PL, Poland; UK, United Kingdom. 
regression. Here, in logistic regression, the Nagelkerke's "pseudo" $R^{2}$ has been applied.

Ethical approval was not required for this study.

\section{Results}

\section{Characteristics of surveyed group}

Thirty-six pharmacies in Poland and 56 pharmacies in the UK, located in areas of different socioeconomic characteristics, were included. Overall, 417 respondents (women, $\mathrm{n}=308 ; 74 \%$ ) in Poland; and 405 respondents (women, $\mathrm{n}=282 ; 70 \%$ ) in the UK, took part in the study. The age range in the total study population was $16-85$ years.

The response rate was $55.6 \%(\mathrm{n}=417 / 750)$ in Poland and $54.0 \%(\mathrm{n}=405 / 750)$ in the UK. The age structure differed between the two populations $(P<0.001) ; 82 \%$ of Polish responders were $<40$ years; whereas, in the UK, $52 \%$ fell into this age group. When compared with the UK, the proportions of married responders in Poland were lower
(33\% versus $54 \%$, respectively; $P<0.001$ ), and higher for those with high education or university degree (51\% versus $20 \%$, respectively; $P<0.001)$. Furthermore, concerning the occupational status, in Poland compared to the UK, there were more students (37\% versus $10 \%$, respectively; $P<0.001)$, fewer employees of the health care system $(13 \%$ versus $32 \%$, respectively; $P<0.001$ ), and more white-collar workers (35\% versus $20 \%$, respectively; $P<0.001$ ). Fewer Polish responders lived in communities with a population up to 100,000 inhabitants than British (41\% versus $75 \%$, respectively; $P<0.001)$. Demographic characteristics are presented in Table 2.

\section{Profile of use of pharmacy services}

The primary reason for visiting a pharmacy in both countries was filling a prescription (reported by $73 \%$ and $78 \%$ respondents in Poland and in the UK, respectively; $P=$ not significant $[\mathrm{NS}]$ ). Other reasons included

Table 2 Demographic characteristics of the surveyed groups

\begin{tabular}{|c|c|c|c|c|c|}
\hline \multirow[t]{2}{*}{ Demographic characteristics } & \multicolumn{2}{|c|}{ Poland $(\mathrm{N}=4 \mid 7)$} & \multicolumn{2}{|c|}{ UK $(N=405)$} & \multirow[t]{2}{*}{$P$-value } \\
\hline & $\#$ & Proportion (\%) & $\#$ & Proportion (\%) & \\
\hline Sex & & & & & NS \\
\hline Women & 308 & 74 & 282 & 70 & \\
\hline Men & 109 & 26 & 123 & 30 & \\
\hline Age groups (years) & & & & & $<0.001$ \\
\hline $15-19$ & 8 & 2 & 29 & 7 & \\
\hline $20-29$ & 271 & 65 & 108 & 27 & \\
\hline $30-39$ & 62 & 15 & 75 & 19 & \\
\hline $40-49$ & 34 & 8 & 79 & 19 & \\
\hline $50-59$ & 28 & 7 & 62 & 15 & \\
\hline$\geq 60$ & 14 & 3 & 52 & 13 & \\
\hline Marital status & & & & & $<0.001$ \\
\hline Married & 136 & 33 & 217 & 54 & \\
\hline Single & 261 & 63 & 153 & 38 & \\
\hline Widow/widower & 7 & 2 & 13 & 3 & \\
\hline Divorced & 10 & 2 & 22 & 5 & \\
\hline Employment & & & & & $<0.001$ \\
\hline Health service & 55 & 13 & $|3|$ & 32 & \\
\hline Professional/education & 145 & 35 & 80 & 20 & \\
\hline Businessman/woman & 20 & 5 & 35 & 9 & \\
\hline Physical worker & 26 & 6 & 94 & 23 & \\
\hline Student & $|5|$ & 37 & 42 & 10 & \\
\hline Pensioner & 16 & 4 & 23 & 6 & \\
\hline Education & & & & & $<0.001$ \\
\hline Up to, including secondary school & 204 & 49 & 326 & 81 & \\
\hline Higher education and above & 212 & 51 & 79 & 19 & \\
\hline Place of residence & & & & & $<0.001$ \\
\hline Village & 60 & 14 & 118 & 29 & \\
\hline Town: population up to 100,000 & 112 & 27 & 183 & 45 & \\
\hline City: population $100,000-500,000$ & 73 & 18 & 89 & 22 & \\
\hline City: population $>500,000$ & 171 & 41 & 14 & 4 & \\
\hline
\end{tabular}

Abbreviations: NS, not significant; UK, United Kingdom; N, number in each country. 
seeking advice for various health problems, such as pain (reported by $57 \%$ and $44 \%$ respondents in Poland and in the UK, respectively; $P<0.002$ ), flu and/or flu-like symptoms (64\% in Poland and $35 \%$ in the UK; $P<0.001)$ and cough and hoarseness of the voice $(29 \%$ in Poland and 5\% in the UK; $P<0.001)$. Almost $30 \%$ of respondents in both countries reported a need for general information about health and healthy lifestyle as the primary reason for their visit $(P=\mathrm{NS})$, and $15 \%$ in Poland and $14 \%$ in the UK $(P=\mathrm{NS})$ visited a pharmacy because of a child's illness. Other reasons, with observed differences between the countries, were: rash (Poland, 3\%; UK, 7\%; $P<0.013$ ); nervousness (Poland, 4\%; UK, 1\%; $P<0.001$ ); and palpitation (Poland, $2 \%$; no reports in the UK; $P<0.001$ ). In general, the Polish patients reported many more reasons for their visits than the British.

The results of logistic regression analysis showed that the differences in visiting a pharmacy because of a rash, cough, sore throat, hoarseness of the voice or nervousness were purely country related, with no impact of other background characteristics. The difference of visiting a pharmacy because of a flu and/or flu-like symptoms was due to a country $(P<0.001)$, but also by the difference in age $(P<0.017)$; ie, Polish participants tended to visit a pharmacy because of this reason regardless of age, but - at the same time - younger participants visited more often because of a flu and/or flu-like symptoms, regardless of the country of origin (Figure 1). As Polish participants were younger, this difference was amplified by the impact of age. Finally, the difference in pain being the main reason of visiting a pharmacy resulted

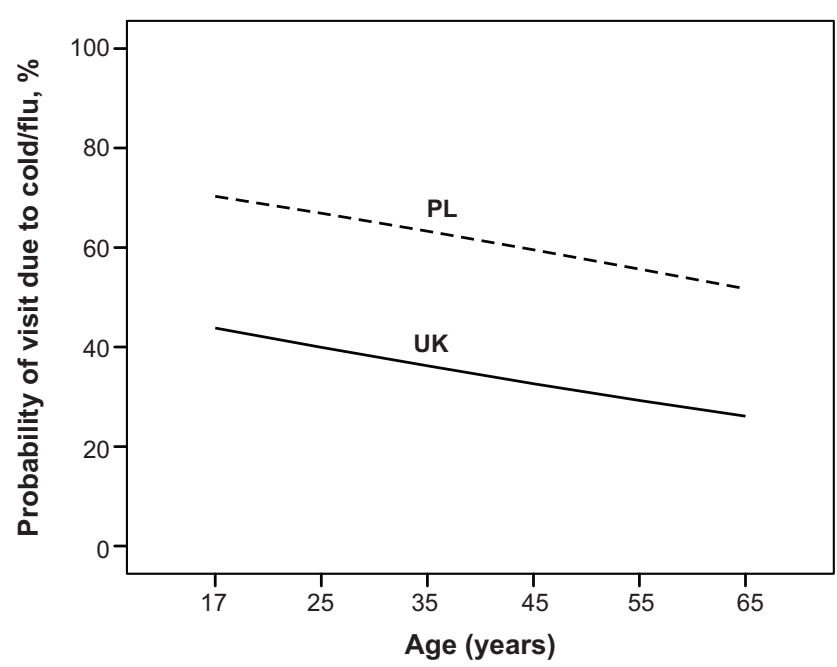

Figure I Probability of visiting a pharmacy because of flu and flu-like symptoms by country and age (proportion of respondents). Abbreviations: PL, Poland; UK, United Kingdom. purely from the difference in age between both populations $(P<0.001)$ and not the country of origin. Younger participants sought advice regarding pain more often than older, independent of the country they came from.

\section{Frequency of pharmacy visits}

The study showed that British respondents visit a pharmacy more often than the Polish respondents. In Poland, $4 \%$ of respondents visited a pharmacy: more than one to two times per week; 34\% twice a month; and 62\% less than twice a month. In the UK, $18 \%$ of responders came to a pharmacy one to two times per week, $20 \%$ twice a month, and $61 \%$ less than twice a month. Overall, British patients visited their pharmacies more often than Polish patients $(P<0.001)$. Logistic regression confirmed these findings and yielded only a country effect $(P<0.001)$; ie, Polish respondents visited pharmacies less often than UK respondents, regardless of the observed differences in background characteristics. When the country was excluded as a predictor, respondents from rural areas were more likely to visit pharmacies $(P<0.001)$ than responders from towns $>100,000$ inhabitants, and students less often than other occupational groups $(P<0.018)$.

The number of prescriptions filled per month was different in Poland and in the UK. In Poland, 95\% of respondents reported filling zero to two prescriptions per month; whereas, in the UK, that number was $80 \%(P<0.001)$. On the other hand, only $0.5 \%$ of Polish respondents filled six or more prescriptions per month; whereas, in the UK, it was $8 \%$. The remaining respondents reported filling three to five prescriptions per month. The probability of filling three or more prescriptions per month was higher in the UK than in Poland (OR 3.46; 95\% CI 2.00-5.97; $P<0.001$ ), increased with age (OR 1.56; 95\% CI 1.34-1.82; $P<0.0001)$, and was higher in participants visiting often the same pharmacy (OR 2.02; 95\% CI 1.15-3.53; P<0.014) (Figure 2).

\section{Loyalty to single community pharmacy}

There was a difference in the level of patients' loyalty to a single community pharmacy as $38 \%$ of Poles declared visiting the same pharmacy versus $61 \%$ in the UK $(P<0.001)$.

Factors influencing loyalty, as defined by frequent visits to the same pharmacy, were sex, age, and education (Figure 3). Women tended to visit the same pharmacy more often than men $(P<0.021)$, and older responders more often than younger $(P<0.001)$. Education had an opposite effect, and responders with a university degree visited the same pharmacy less often than those with a lower level of education $(P<0.001)$. 


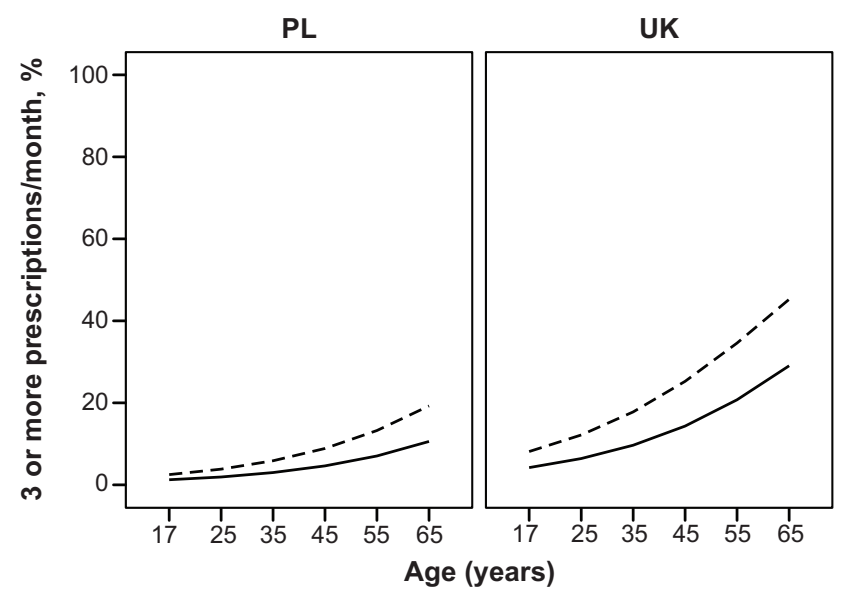

Figure 2 Probability of filling $\geq$ three prescriptions per month by country, age of respondent, and loyalty to pharmacy (proportion of respondents). Continous line indicates loyal clients (often visiting the same pharmacy) and broken line (those who do not often visit the same pharmacy).

Abbreviations: PL, Poland; UK, United Kingdom.

\section{Factors influencing choice of a pharmacy}

The study showed that, in almost all aspects, the opinions of Polish and British respondents regarding factors that influence their choice of a pharmacy differed $(P<0.05)$. A similar level of preference between the two populations was observed only for two factors: 1) convenient pharmacy location; and 2) promotions on medicines (Table 3 ).

The convenient location of pharmacy, professional service, and good price of medicines were the most frequently reported factors by Polish respondents; whereas, professional service, convenient location, and good advice received in a pharmacy were the most frequently reported factors by the British respondents (Table 3).

Evaluation of the strength of each factor's influence on making a pharmacy choice by the patient, as expressed by Polish and British respondents, is shown in Figure 4.

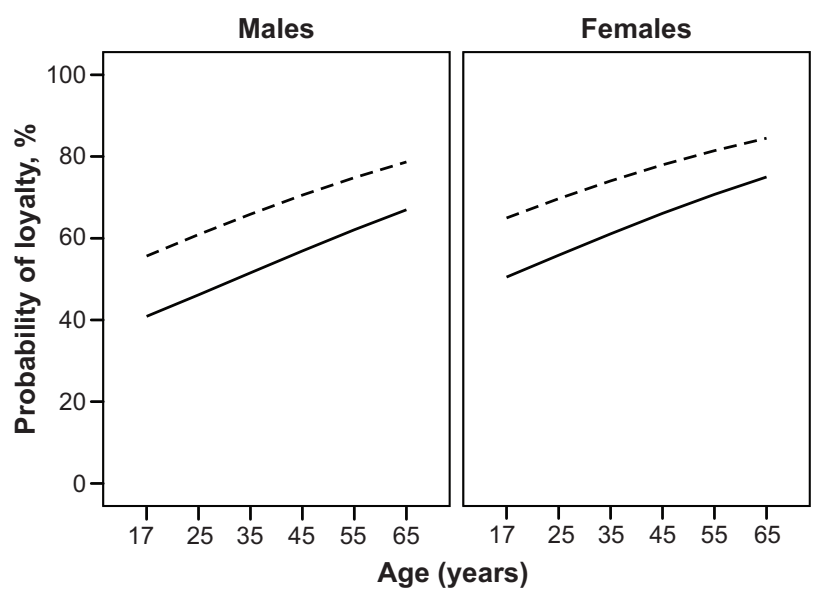

Figure 3 Loyalty to a single pharmacy according to sex, age, and education (university degree, yes/no) (proportion of respondents). Continuous line indicates clients with university degree and broken line indicates those who have education below university.

\section{Logistic multivariate regression analyses}

The study showed that in almost all aspects the opinions of the Polish and British respondents regarding factors that influence their choice of a pharmacy differed.

This is also shown in Table 4, where country is the predominant factor explaining the choice of pharmacy and entering the regressions first. The results showed that British respondents were more likely than the Polish to choose a pharmacy because of a possibility to receive good advice (OR 3.1; 95\% CI 1.93-5.10), a possibility to discuss their health problems in a separate consultation room (OR 4.4; 95\% CI 2.88-6.67) and a professional service (OR 1.9; 95\% CI 1.04-3.65). Polish respondents were more likely than the British to base their choice of pharmacy on the aesthetic decoration of the pharmacy (OR 0.6; 95\% CI 0.45-0.96). Furthermore, aesthetic decoration of the pharmacy was more important to respondents who often visited a pharmacy (one to two times a week) than to those who visited a pharmacy less frequently (OR 2.2; 95\% CI 1.23-3.98).

The only exception from country dependence was the location of the pharmacy where country was not identified as a predictor, but the results showed that the employees of the health care systems (OR 2.4; 95\% CI 1.05-5.71) and white collar employees (OR 5.4; 95\% CI 1.86-15.44) had preferences for the location. In the analyses of the preference for low prices, Polish respondents (OR 0.6; 95\% CI $0.36-0.90$ ), white collar employees (OR 1.8; 95\% CI 1.06-3.21), and respondents who frequently visited pharmacies (OR 3.0; 95\% CI 1.37-6.65) were more likely to select a pharmacy based on, in the respondents' opinion, the good price of medicines.

In the analysis of preference for promotions on medicines, Polish respondents (OR 0.6; 95\% CI 0.43-0.82), women (OR 1.8; 95\% CI 1.30-2.56), respondents who visited a pharmacy frequently (OR 2.3; 95\% CI 1.31-4.02), and loyal visitors (OR 1.52; 95\% CI 1.10-2.10) were more likely to choose a pharmacy based on promotions available.

\section{Discussion Major findings}

This study identifies factors that influence the choice of a pharmacy by respondents in Poland and in the UK. Knowledge of these factors can be used in pharmaceutical marketing and in advancing the implementation of full pharmaceutical care in Poland. This knowledge can also be helpful in formulating advice for the UK organizations on maintaining a high standard of patient care, particularly related to drug safety and polypharmacy. 
Table 3 Profile of reported factors influencing the choice of a pharmacy in Poland and the UK

\begin{tabular}{|c|c|c|c|c|c|}
\hline Factor & Poland $(\mathrm{N}=4 \mid 7)$ & Total $\mathbf{n}$ & UK $(N=405)$ & Total $\mathbf{n}$ & $P$-value \\
\hline Good advice received in pharmacy $([\%\{n\}])$ & $68(269)$ & 397 & $88(350)$ & 400 & $<0.001$ \\
\hline $\begin{array}{l}\text { Possibility of discussing personal health issues } \\
\text { in private consultation room }([\%\{\mathrm{n}\}])\end{array}$ & $50(194)$ & 389 & 81 (323) & 397 & $<0.001$ \\
\hline Aesthetic decoration of pharmacy $([\%\{n\}])$ & $65(260)$ & 397 & $58(230)$ & 400 & $<0.042$ \\
\hline Professional service $([\%\{n\}])$ & $85(340)$ & 399 & $92(365)$ & 397 & $<0.004$ \\
\hline Location $([\%\{n\}])$ & $88(350)$ & 397 & $90(360)$ & 400 & NS \\
\hline Good price on medicines $([\%\{n\}])$ & $82(327)$ & 397 & $71(283)$ & 396 & $<0.001$ \\
\hline Promotions on medicines $([\%\{\mathrm{n}\}])$ & $70(275)$ & 393 & $60(230)$ & 386 & NS \\
\hline
\end{tabular}

Abbreviations: NS, not significant; UK, United Kingdom; N, number in each country; n, number.

For the Polish patients, the location of the pharmacy, a professional and high quality service, and the good prices of medicines were the three most frequently reported factors influencing their choice of pharmacy. For British responders, the top three were: professionalism and high quality of service; location; and good advice received from the pharmacist. Another important finding is the difference in the level of patients' loyalty to a single pharmacy. Almost twice as many British as Polish responders declared visiting the same pharmacy, although this difference did not appear to be country-specific, as shown by the results of regression analysis. Finally, it was found that Polish respondents reported factors that are components of pharmaceutical care (good advice received from pharmacies and a separate consultation room) less frequently than British responders.

The study confirms the findings from other UK studies, namely, proximity to home or work as well as the pharmacist's friendliness and sympathy as important factors influencing the choice of pharmacy. ${ }^{28,29}$ In Poland, Piecuch et $\mathrm{al}^{30}$ similarly to the present findings, reported convenient location and the price of medicines as being the most important factors and the level of professional service as less important. Noteworthy, Kwilecki et al ${ }^{13}$ described the availability of medicines as the most important factor - more important than the professional advice or pleasant staff. It is, however, worth highlighting that the present study was performed on much larger population samples than the studies by Piecuch et al and by Kwilecki et al. Furthermore, it covered more disperse regions from both Poland and the UK. Therefore, the findings presented should be considered to be more representative. The current study also contributes direct comparisons of the two countries' populations.

\section{Pharmaceutical care and choice of pharmacy}

The present study confirms that the more frequent factors determining the choice of pharmacy in the UK are good pharmaceutical advice, an opportunity to consult with a pharmacist, and professional service - rather than the price and promotions on medicines. The first three factors are part of essential services provided by community pharmacies that are components of pharmaceutical care in the UK. ${ }^{32}$ Studies in the UK show that one of the most important elements of satisfaction with a pharmacy is professional advice obtained from its staff and friendly professional service. ${ }^{28,29}$ On the other hand, there is a scarcity of data on the role of components of pharmaceutical care in patient choice of pharmacies in Poland, which makes the present study a unique contribution to a better understanding of patient preferences. By confirming the results of previous studies performed in the UK and relating them to the situation in Poland, a country where pharmaceutical care is not advanced, the present findings indicate a direction to which the development of patient care including pharmaceutical support should progress to amplify patient benefits.

\section{Patients' loyalty to pharmacy}

Although a higher degree of loyalty to a single community pharmacy was observed in the UK than in Poland, these differences were explained by sex, age and the level of education. Similarly to the results published by $\mathrm{Xu},{ }^{33}$ in this study women tended to use a single community pharmacy more often than men. The observation related to age (older responders tended to use the same community pharmacy), albeit concurrent, cannot be directly linked to Xu's findings as the latter study was performed in an elderly population. It could be speculated that, since British patients indicated more components of pharmaceutical care as criteria for their choice of pharmacy, a higher absolute proportion of the British respondents could be explained by the full pharmaceutical care being already implemented in the UK.

Furthermore, loyalty to the same pharmacy correlated with the three main elements of pharmaceutical care. 
A)

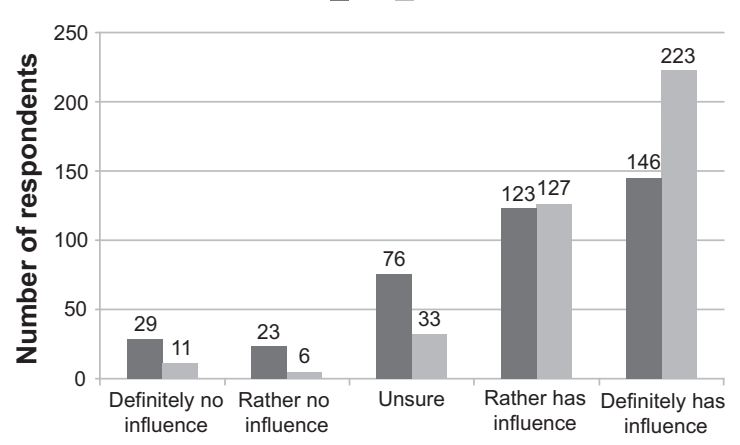

C)

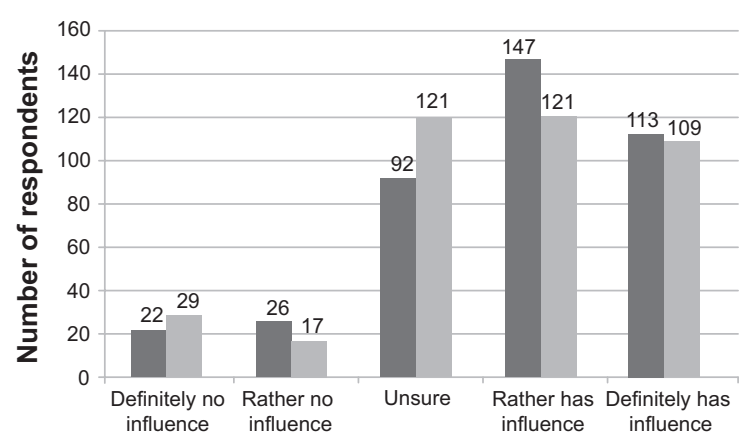

E)

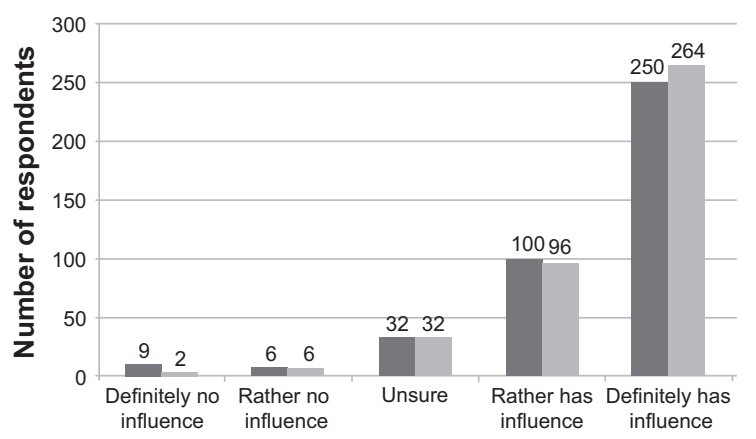

B)

PL UK

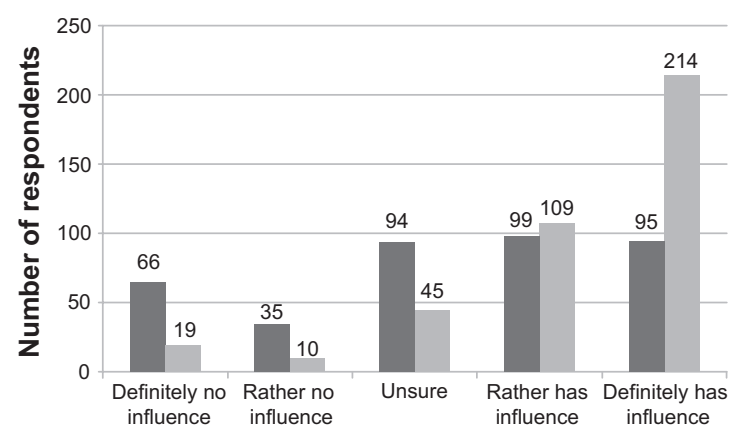

D)

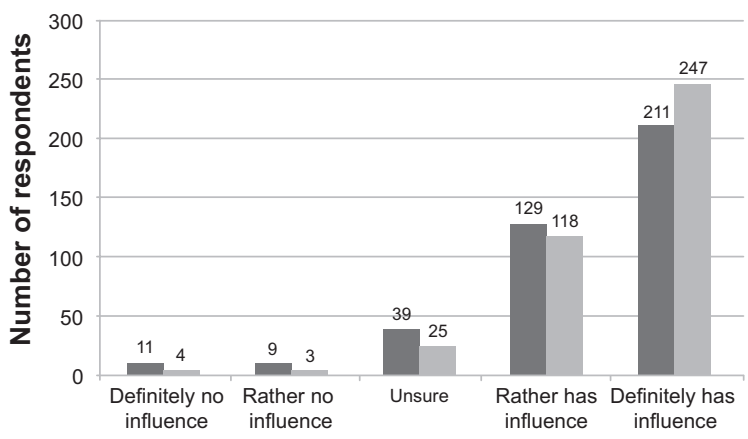

F)

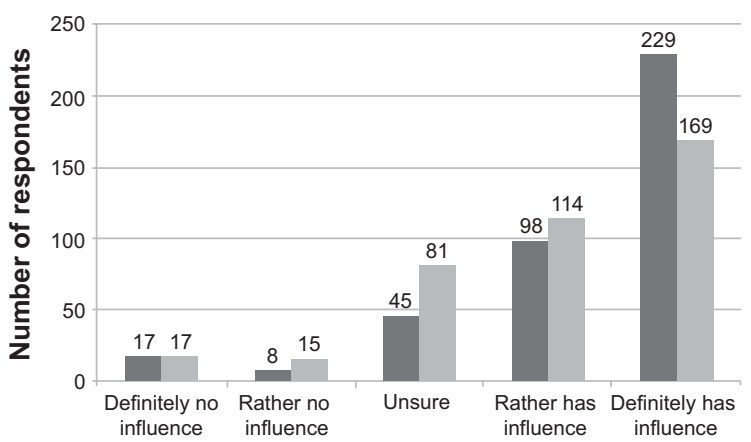

G)

PL UK

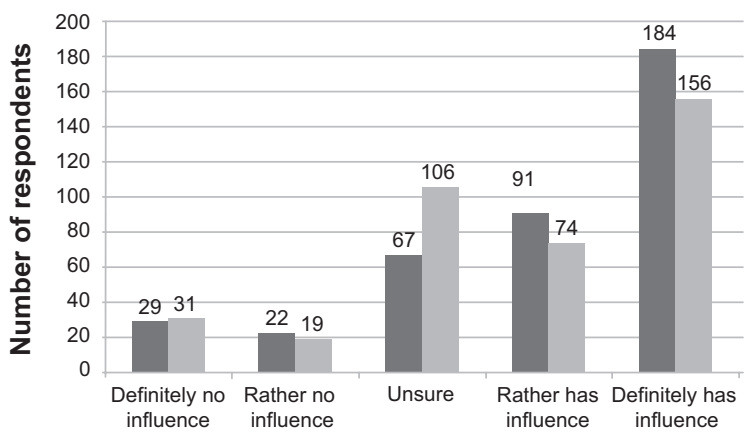

Figure 4 Evaluation of the strength of influence of the following factors.

Notes: (A) Good advice offered in pharmacy. (B) Possibility of discussing personal health issues in a private consultation room. (C) Decoration of the pharmacy and appearance of pharmacy staff. (D) Professional service. (E) Convenient location of the pharmacy. (F) Good price of medicines. (G) Promotions on medicines.

Abbreviations: PL, Poland; UK, United Kingdom. 


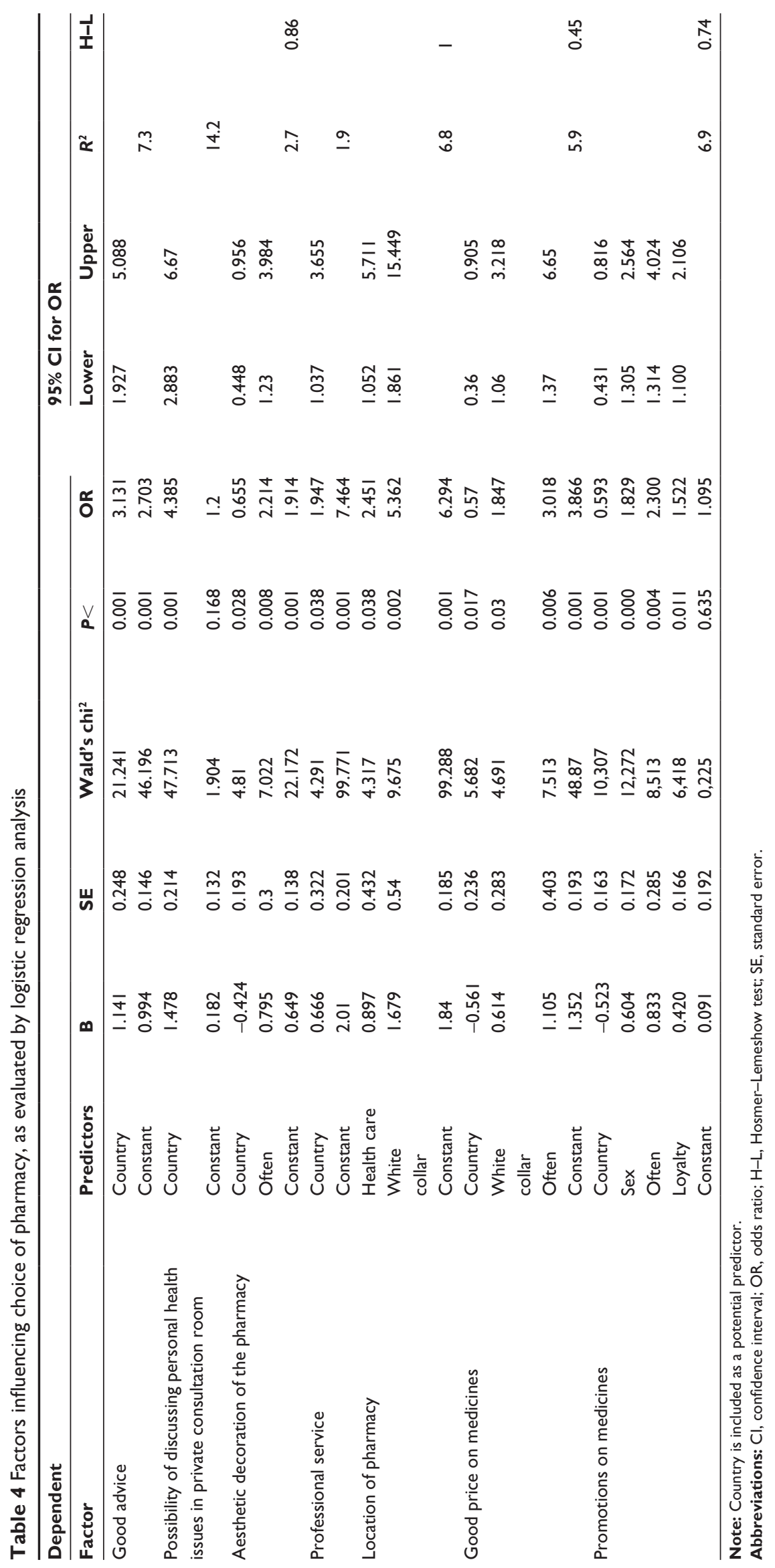


These findings are concurrent with other studies on consumer perception and attitudes toward community pharmacy, which showed that patients were more satisfied with pharmacies where pharmaceutical care was introduced. When pharmaceutical care was introduced, their loyalty to a single pharmacy increased. ${ }^{34,35}$ In summary, it can be speculated that the components of pharmaceutical care are important criteria for patients' choice of pharmacy, and they have the potential to encourage patients' loyalty.

\section{Price of medicines}

The price of medicines and promotion on medicines seem to be important factors in the choice of pharmacy for almost $80 \%$ of Polish respondents, but less important for British consumers. This fact can be explained by different health insurance systems in the two countries, as already described in the introduction.

\section{Predictors of patient choice of community pharmacy}

The results of regression analysis confirmed that components of pharmaceutical care are more important factors influencing the patient choice of pharmacy for British patients than for Polish patients. The British were: three times more likely to choose a community pharmacy because of a possibility of obtaining good advice; more than four times because of an access to a separate consultation room for discussing their health problems; and almost twice more likely to base their choice on receiving professional service. These findings highlight the importance of pharmaceutical care in the process of pharmacy selection. The Polish respondents tended to choose a pharmacy based on its aesthetic decoration. Interestingly, no cross-country differences were observed with regard to the location of the pharmacy, which was equally important in both countries. This finding agrees with the already published data, that convenient location is a key factor of choosing a pharmacy, regardless of country, and equally for all people. It is also noteworthy that patients, who declared visiting a pharmacy often, considered low prices and promotions on medicines as an important factor, while for loyal patients only promotions counted.

\section{Limitations of study}

The difference between the Polish and the British demographic characteristics, particularly the age distribution and the proportion of respondents being employed in health care, may have impacted the results, and this may partly explain the results. In other words, the observed variations may be specific to age or type of employment and not necessarily the country of origin, as such. Nevertheless, the samples of pharmacy customers in each of the countries represented pharmacy customers at large in each of the countries and, therefore, indicated preferences of relevant populations.

Furthermore, the design of the study and the factor selection were mainly driven by the specificity of the European health care systems where, for example, health insurance coverage plays a less critical role. Similarly, different types of pharmacies were not included, since primary mail order pharmacies are not - as yet - very popular in Europe. Therefore, it cannot be excluded that more factors than the number included in the applied questionnaire may have impacted patient preferences, ${ }^{32}$ particularly in the countries where the profile of pharmacies and health care system are different; for example, as it was shown in the study published by $\mathrm{Xu}$.

Finally, it should be also taken into consideration that the population sample originated from the clients of pharmacies, not from the population at large, who may represent a selection bias since the respondents, particularly from the UK, were likely to fill the questionnaire while visiting their regular pharmacy. The study, however, focuses on pharmacy clients and, therefore, this limitation is perceived as a minor one and does not limit the generalizability of the study regarding the population of pharmacy clients.

The study was carried before the new legislation on drug reimbursement was launched in 2012 in Poland. Therefore, the study reflects the situation under the previous drug reimbursement system when the prices of prescription medicines varied from one pharmacy to another. Currently, the prices for prescription medicines are the same in every pharmacy in Poland. However, it is speculated that the outcome of this change will be observed in 3 years' time, and thus, the importance of medicines' prices as a pharmacy selection criterion is likely to remain during this time. Therefore, it would be worth repeating this study in 3-5 years' time to evaluate the impact of the change in the Polish pharmacy legislation.

\section{Conclusion}

Overall, the most important factors influencing patient choice of pharmacy were similar in both countries with a few differences related to the importance ranking. A good price of medicine was reported as a criterion more often in Poland than in the UK, and the components of 
pharmaceutical care were one of the most important factors influencing the patient choice of pharmacy in the UK and - to a lesser degree - in Poland. At the same time, more patients in the UK than in Poland are committed to a single pharmacy. Therefore, implementing the full pharmaceutical care in Poland may contribute to an increase in patients' loyalty and thus strengthen competitiveness of pharmacy businesses.

\section{Acknowledgments}

We wish to express our sincere appreciation and thanks to the following organizations for providing their help and guidance at every stage of our research: the Royal Pharmaceutical Society (UK); the Pharmaceutical Services Negotiating Committee (UK); the Department of Health (UK); and the Polish Pharmaceutical Society (Poland). We would also like to thank Bjorn Jonsson, Department of Women's and Children's Health, Uppsala University (Uppsala, Sweden), for the statistical expertise and statistical analysis, and Izabela Zdolińska-Malinowska of Proper Medical Writing (Warsaw, Poland) for formatting the final version of our manuscript.

\section{Disclosure}

The authors report no conflicts of interest in this work.

\section{References}

1. Björkman IK, Bernsten CB, Sanner MA. Care ideologies reflected in 4 conceptions of pharmaceutical care. Res Social Adm Pharm. 2008;4(4):332-342.

2. Hepler CD, Strand LM. Opportunities and responsibilities in pharmaceutical care. Am J Hosp Pharm. 1990;47(3):533-543.

3. Cipolle RJ, Strand LM, Morley PC. Pharmaceutical Care as a Professional Practice. In: Pharmaceutical Care Practice: The PatientCentered Approach to Medication Management Services. 3rd ed. New York: McGraw-Hill; 2012:45.

4. Roughead EE, Semple SJ, Vitry AI. Pharmaceutical care services: a systematic review of published studies, 1990 to 2003, examining effectiveness in improving patient outcomes. Int $J$ Pharm Pract. 2005;13(1):53-70

5. Posey LM. Proving that pharmaceutical care makes a difference in community pharmacy. J Am Pharm Assoc (Wash). 2003;43(2):136-139.

6. Cordina M, McElnay JC, Hughes CM. Assessment of a community pharmacy-based program for patients with asthma. Pharmacotherapy. 2001;21(10):1196-1203

7. Cranor CW, Christensen DB. The Asheville Project: short-term outcomes of a community pharmacy diabetes care program. J Am Pharm Assoc (Wash). 2003;43(2):149-159.

8. Simpson SH, Johnson JA, Biggs RS, Tsuyuki RT; SCRIP Investigators. Greater effect of enhanced pharmacist care on cholesterol management in patients with diabetes mellitus: a planned subgroup analysis of the Study of Cardiovascular Risk Intervention by Pharmacists (SCRIP). Pharmacotherapy. 2004;24(3):389-394.

9. Crockett JA, Taylor SJ, McLeod LJ. Patient responses to an integrated service, initiated by community pharmacists, for the prevention of osteoporosis. Int J Pharm Pract. 2008;16(2):65-72.

10. Mruk H. Opieka farmaceutyczna a pozycja apteki (Pharmaceutical care and the position of the pharmacy). Manager Apteki. 2010;6:60-61. Polish.
11. Ustawa z dnia 6 września 2001 r. Prawo farmaceutyczne, Rozdział 7: Apteki (The Act of September 6, 2001. Pharmaceutical law, Chapter 7: The Pharmacies). Dziennik Ustaw. 2001:126:pos.1381. Polish.

12. National Health Service. Pharmacy in the Future: Implementing the NHS Plan. London: Department of Health; 2000. Available from: http://webarchive.nationalarchives.gov.uk/20130107105354/http:// www.dh.gov.uk/prod_consum_dh/groups/dh_digitalassets/@dh/@en/ documents/digitalasset/dh_4068204.pdf. Accessed March 21, 2013.

13. The National Health Service (Pharmaceutical Services) Regulations 2005. Number 641. [webpage on the Internet]. London: The National Archives; 2005 Available from: http://www.legislation.gov.uk/ uksi/2005/641/contents/made. Accessed March 20, 2013.

14. Pharmaceutical Services Negotiating Committee 2008. Available from: http://psnc.org.uk/services-commissioning/. Accessed April 11, 2014.

15. Wirth F, Tabone F, Azzopardi LM, Gauci M, Zarb-Adami M, SerracinoInglott A. Consumer perception of the community pharmacist and community pharmacy services in Malta. Journal of Pharmaceutical Health Services Research. 2010;1(4):189-194.

16. El Hajj MS, Salem S, Mansoor H. Public's attitudes towards community pharmacy in Qatar: a pilot study. Patient Prefer Adherence. 2011;5:405-422.

17. Pronk MCM, Blom ATG, Jonkers R, Bakker A. Evaluation of patient opinions in a pharmacy-level intervention study. Int $J$ Pharm Pract. 2003;11(3):143-151.

18. Whitehead P, Atkin P, Krass I, Benrimoj SI. Patient drug information and consumer choice of pharmacy. Int J Pharm Pract. 1999;7(2): 71-79.

19. Ried LD, Wang F, Young H, Awiphan R. Patients'satisfaction and their perception of the pharmacist. J Am Pharm Assoc (Wash). 1999;39(6):835-842.

20. Bornman S, Truter I, Venter DJL. Public perception of community pharmacists in South Africa: a preliminary study. Health $S A$ Gesondheid. 2006;11(3):27-40.

21. Kamei M, Teshima K, Fukushima N, Nakamura T. Investigation of patients' demand for community pharmacies: relationship between pharmacy services and patient satisfaction. Yakugaku Zasshi. 2001;121(3):215-220.

22. Mobach MP. The counter and consultation room work explored in the Netherlands. Pharm World Sci. 2008;30(4):360-366.

23. Merks P, Olszewska A, Dehili Ch, et al. Consultation room as one of the important aspects of implementation of advanced pharmaceutical services in Poland. Farmacja Polska. 2013;69:399-407. Polish.

24. Narodowy Fundusz Zdrowia (National Health Fund). General information concerning access to health care during a temporary stay in Poland; 2013. Available from: https://www.ekuz.nfz.gov. pl/en/info_dla_uprawnionych_z_innych/general-informationconcerning-access-health-care-during-temporary-st. Accessed March 21, 2013.

25. Kaminski W. Mamy najdroższe leki w Europe (We have the most expensive medicines in Europe). Niezalezna. 10.11.2012. Available from: http://niezalezna.pl/34686-mamy-najdrozsze-leki-w-europie. Accessed March 21, 2013. Polish.

26. National Health Service. Prescription costs: make savings; London: National Health Service; 2012 [updated February 11, 2012]. Available from: http://www.nhs.uk/planners/yourhealth/pages/prescriptioncosts. aspx. Accessed March 21, 2013.

27. Hosmer DW, Lemeshow S. Applied Logistic Regression. New York, NY: John Wiley \& Sons Inc; 1989.

28. Anderson C. Health promotion by community pharmacists: consumers' views. Int J Pharm Pract. 1998;6(1):2-12.

29. Smith FJ. Factors important to clients when seeking the advice of a pharmacist. Pharm J. 1990;244:692-693.

30. Piecuch A, Kozlowska-Wojciechowska M. Self-medication in Poland: the pharmacist's advisory role in Warsaw. Int J Clin Pharm. 2013;35(2):225-229. 
31. Kwilecki W. Oczekiwania pacjentów wobec aptek i farmaceutów (Patients' expectations from pharmacies and pharmacists). Gazeta Farmaceutyczna. 2010;217:12-5. Polish.

32. Pharmaceutical Services Negotiating Committee 2008. Available from: http://www.psnc.org.uk/pages/essential_services.html. Accessed January 10, 2013.

33. $\mathrm{Xu} \mathrm{TK}$. Choice of and overall satisfaction with pharmacies among a community-dwelling elderly population. Med Care. 2002;40(12): 1283-1293.
34. Hargie O, Morrow N, Woodman C. Consumer perceptions of and attitudes to community pharmacy services. Pharmaceutical Journal. 1992;249:688-691.

35. Pray WS. The pharmacist as self-care advisor. J Am Pharm Assoc (Wash). 1996;36(5):329-340.

\section{Publish your work in this journal}

Patient Preference and Adherence is an international, peer-reviewed, open access journal that focusing on the growing importance of patient preference and adherence throughout the therapeutic continuum. Patient satisfaction, acceptability, quality of life, compliance, persistence and their role in developing new therapeutic modalities and compounds to optimize clinical outcomes for existing disease states are major areas of interest for the journal. This journal has been accepted for indexing on PubMed Central. The manuscript management system is completely online and includes a very quick and fair peer-review system, which is all easy to use. Visit http://www. dovepress.com/testimonials.php to read real quotes from published authors.

Submit your manuscript here: http://www.dovepress.com/patient-preference-and-adherence-journal 